\title{
Coronavirus Disease 2019 (COVID-19) and its implications for cardiovascular care: expert document from the German Cardiac Society and the World Heart Federation
}

\author{
Michael Böhm ${ }^{1} \cdot$ Norbert Frey $^{2} \cdot$ Evangelos Giannitsis $^{3} \cdot$ Karen Sliwa $^{4} \cdot$ Andreas M. Zeiher $^{5}$
}

Received: 17 April 2020 / Accepted: 24 April 2020 / Published online: 27 May 2020

(c) Springer-Verlag GmbH Germany, part of Springer Nature 2020

\begin{abstract}
Coronavirus diseases 2019 (COVID-19) has become a worldwide pandemic affecting people at high risk and particularly at advanced age, cardiovascular and pulmonary disease. As cardiovascular patients are at high risk but also have dyspnea and fatigue as leading symptoms, prevention, diagnostics and treatment in these patients are important to provide adequate care for those with or without COVID-19 but most importantly when comorbid cardiovascular conditions are present. Severe COVID-19 with acute respiratory distress (ARDS) is challenging as patients with elevated myocardial markers such as troponin are at enhanced high risk for fatal outcomes. As angiotensin-converting enzyme 2 (ACE2) is regarded as the viral receptor for cell entry and as the Coronavirus is downregulating this enzyme, which provides cardiovascular and pulmonary protection, there is ongoing discussions on whether treatment with cardiovascular drugs, which upregulate the viral receptor ACE2 should be modified. As most of the COVID-19 patients have cardiovascular comorbidities like hypertension, diabetes, coronary artery disease and heart failure, which imposes a high risk on these patients, cardiovascular therapy should not be modified or even withdrawn. As cardiac injury is a common feature of COVID-19 associated ARDS and is linked with poor outcomes, swift diagnostic management and specialist care of cardiovascular patients in the area of COVID-19 is of particular importance and deserves special attention.
\end{abstract}

Keywords CORONA $\cdot$ COVID-19 $\cdot$ Heart failure $\cdot$ Hypertension $\cdot$ Cardiovascular risk $\cdot$ Myocardial injury

\section{COVID-19 and cardiovascular care}

For the German Cardiac Society: Michael Böhm, Norbert Frey, Evangelos Giannitsis and Andreas M. Zeiher. For the World Heart Federation: Michael Böhm and Karen Sliwa.

Michael Böhm

michael.boehm@uks.eu

1 Klinik für Innere Medizin III, Kardiologie, Angiologie und Internistische Intensivmedizin, Universitätsklinikum des Saarlandes, Saarland University, Kirrberger Str. 1, 66421 Homburg, Saar, Germany

2 Klinik für Innere Medizin III, Universitätsklinikum Schleswig-Holstein, Kiel, Germany

3 Innere Medizin III, Medizinische Klinik, Universitätsklinikum Heidelberg, Heidelberg, Germany

4 Faculty of Health Sciences, Hatter Institute for Cardiovascular Research in Africa, University of Cape Town, Cape Town, South Africa

5 Department of Medicine-Cardiology,, J.W. Goethe University, Frankfurt, Germany
After the first cases of respiratory illness were reported in December 2019, a novel coronavirus, designated as severe acute respiratory syndrome coronavirus 2 (SARS-CoV-2), was identified to cause the so-called coronavirus disease (COVID-19), which meanwhile has become a worldwide pandemic $[1,2]$. In general, three distinct phases characterize progression of COVID-19: an initial infection phase followed by a respiratory distress phase and finally culminating in a severe hyperinflammation state with more than $80 \%$ of SARS-CoV-2 infections showing only mild or even absent symptoms [3]. The characteristics from the COVID19 outbreak reported from China [3] provided important lessons with respect to cardiovascular involvements both as a primary target as well as a comorbidity. The infection phase marks virus infiltration and proliferation of the epithelium and lung parenchyma accompanied by mild symptoms and monocyte / macrophage activation as the initial immune response. The ensuing inflammatory processes like 
vasodilation, endothelial leakiness and leukocyte extravasation lead to pulmonary distress with pulmonary damage, fluid extravasation and hypoxemia, which in turn augments cardiovascular stress. Finally, further amplification of the host inflammatory response will essentially culminate in systemic inflammation up to eliciting a cytokine storm [4].

Importantly, the cardiovascular system emerges as both a primary target as well as the most important secondary comorbidity factor during all three of the COVID-19 progression phases (Fig. 1). There is accumulating evidence that the heart itself might be a direct target for viral infection with SARS-CoV-2 [5]. Previous studies examining the cardiovascular effects of viral respiratory infections during influenza epidemics revealed a profound up to sixfold increased incidence ratio for acute myocardial infarction within 7 days of infection, in part due to the heightened prothrombotic activity leading to intracoronary thrombotic events [6]. Hypotension and tachycardia will further imbalance the metabolic demand of a diseased heart. Exaggerated systemic inflammation with profoundly increased circulating levels of prototypical inflammatory markers such as IL-6, IL-2, TNFalpha; MCP-1 or CRP are well established to contribute to cardiac injury irrespective of the presence of hypoxemia. Indeed, some of these biomarkers were shown to be associated with high mortality in retrospective clinical series of COVID-19 patients hospitalized in China [7], indicating potential serious bystander effects on other organs, including the heart. In support of such collateral damage to the heart, increased inflammatory markers do correlate with electrocardiographic abnormalities and biomarkers of cardiac injury [8]. Finally, elevation of cardiac biomarkers documenting cardiac involvement is not only a prominent feature in COVID-19, but is also associated with a profoundly worse clinical outcome [9, 10]. Myocardial damage and heart failure contributed to almost $40 \%$ of deaths in a critically ill cohort hospitalized in Wuhan [11]. Cox regression analyses revealed that the mortality risk associated with acute cardiac damage was significantly higher than age, chronic pulmonary disease or prior history of cardiovascular disease $[8,9]$. Thus, both direct and indirect mechanisms of cardiovascular injury most likely play a pivotal role for the deleterious consequences of SARS-CoV-2 infection in addition to the severe acute respiratory distress syndrome (ARDS).

Last, patients with underlying cardiovascular disease are more likely to be infected with SARS-CoV-2, are more likely to develop severe symptoms, if infected with SARS-CoV-2, and may also be more vulnerable to adverse cardiotoxic effects of treatment with antiviral drugs. A most recent analysis from the LEOSS registry [12] displaying the prevalence of co-morbidities in COVID-19 patients in Germany disclosed that in all classes of disease severity more than $50 \%$ of the patients suffered from cardiovascular co-morbidity,

\section{Consequences of SARS-CoV-2 infection for the cardiovascular system}

\begin{tabular}{|l|}
\hline - Primary target \\
- bradycardia, arrhythmia, sudden cardiac death \\
- Direct myocardial infection with SARS-CoV-2, \\
myocarditis \\
- Mononuclear infiltrates of the heart, systemic \\
inflammation \\
- Coronary microvascular thrombosis \\
\end{tabular}

Suggested pathophysiology

- SARS-CoV-2 binds ACE2 expressed in the heart

- Increase in pro-inflammatory cytokines \& systemic inflammation

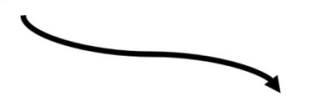

\section{Secondary co-morbidity}

- CVD common in SARS-CoV-2-infected cohort

- Patients with pre-existing CVD at higher risk for adverse events of infections with respiratory viruses

- Viral infection may contribute to unstable chronic CVD (imbalance metabolic demand, cardiac reserve)

- Inflammatory cytokine release aggravates heart failure (depressed contractile function)

\section{Suggested pathophysiology}

- $\mathrm{CVD}=$ classical disease of the elderly

- Systemic inflammation $\longrightarrow$ plaque rupture

- Pro-coagulant effects of systemic inflammation

Survivors of COVID-19

Long-term cardiovascular phenotyping:

Cardiac MRI, biomarkers, genetics, single cell sequencing

Fig. 1 Summary of consequences of SARS-Cov2 infection on the cardiovascular system summarizing primary targets (left) and secondary comorbidities (right) 
which was by far the most prominent co-morbidity associated with COVID-19 (Fig. 2).

Taken together, cardiovascular involvement is both highly prevalent and of significant prognostic importance in COVID-19. Therefore, it is not only important to fully involve cardiologists for managing cardiovascular complications in severe cases of COVID-19, but also to pay particular attention to cardiovascular protection of patients at risk to develop COVID-19. It will be essential to allocate sufficient resources for cardiovascular diagnostic and therapeutic procedures, even at times when the health care systems are globally overwhelmed and hospitals are guided by measures to contain and treat this infectious disease. We need to advice patients that cardiovascular emergencies like STEMI, decompensated heart failure or life-threatening arrhythmias need immediate attention and treatment and emergency calls should not be delayed out of fear for being admitted to a hospital with the potential to acquire COVID-19. We do need to set-up emergency treatment strategies for non-COVID-19 patients in-hospital and assure protection of these patients from SARS-CoV2-infected patients. Additionally, we need to make sure to that hospital staff and health care workers in general are adequately protected and diagnostic and interventional procedures in COVID-19 patients are guided by clinical necessity. Fortunately, all major cardiovascular professional societies are meanwhile in the process of publishing guidance for various aspects of cardiovascular care in COVID-19 patients, including how and in whom to perform diagnostic and therapeutic interventions. Some of these guidance publications will be referenced to in the following chapters of this article. This will without any doubt lead to greater awareness of the immediate cardiovascular implications of this infectious disease.

Nevertheless, we should not stop here. Hospitalization for pneumonia was previously shown to be associated with a significantly increased risk of cardiovascular disease up to 10 years of follow-up [13]. It is very likely that SARSCoV-2 infections with respiratory impairment will also lead to similar long-term adverse events. We need to monitor COVID-19 patients with acutely elevated markers of cardiac damage with respect to long-term consequences on cardiac function, including definite proof of SARSCoV-2-induced myocarditis by myocardial biopsy. Likewise, it will be important to assess potential long-term cardiotoxic effects of antiviral therapy. Thus, cardiovascular care during the COVID-19 pandemic should already implement strategies to capture longer-term implications by prolonged clinical follow-up.

\section{Prevalence of comorbidities on COVID-19 in Germany: Data from the LEOSS Registry Distribution of Comorbidities in Clinical Phases ( $N=354)$ ( $n=413$ ongoing cases are not included in this graph as of 14th april 2020)}

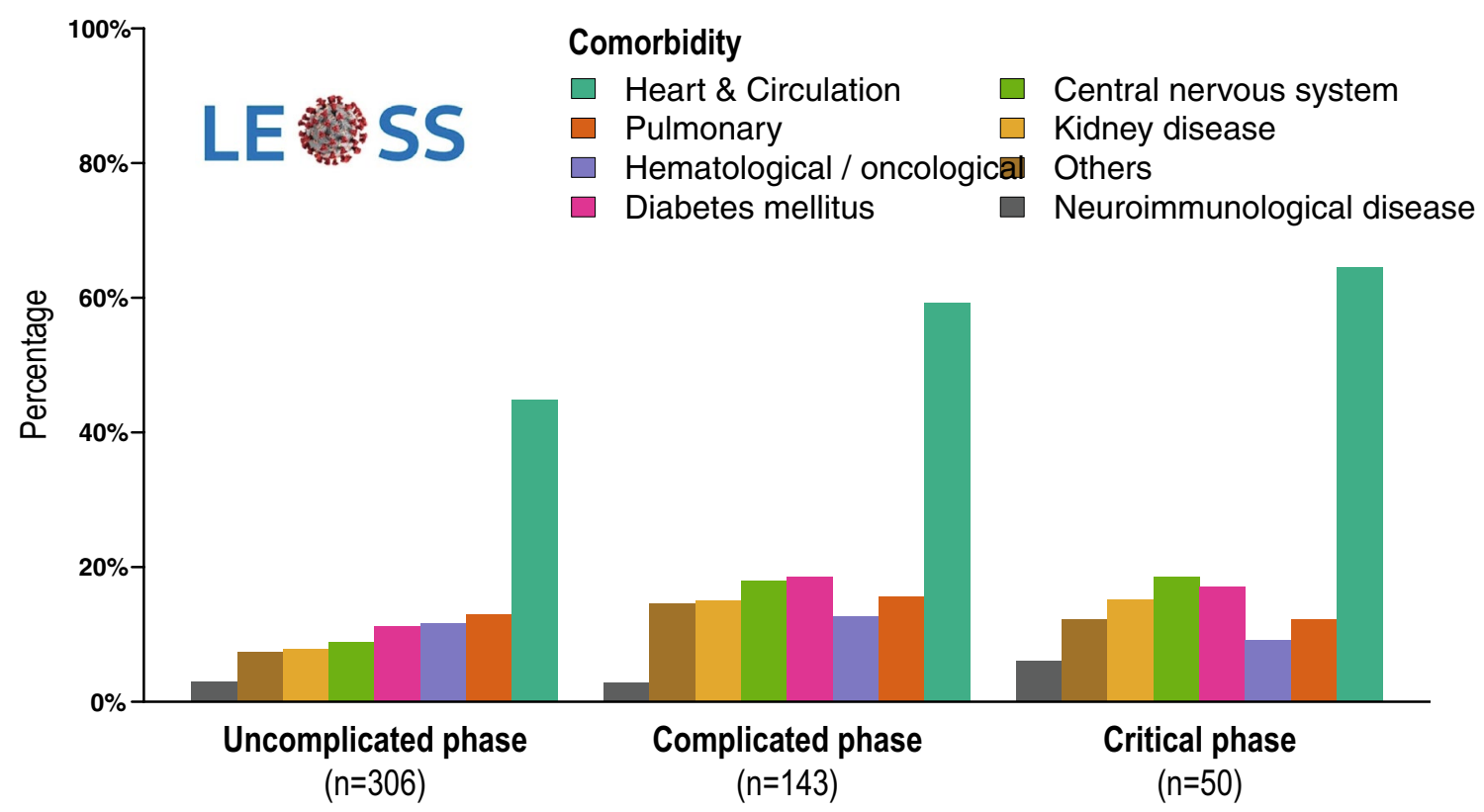

Fig. 2 Distribution of comorbidities in different intensities of COVID-19 infections 


\section{COVID and low-middle income countries}

COVID-19 has spread to almost all countries of the world. Unexplained is the different impact of the disease in different countries. There has been a slow increase in infections in Africa and South-East Asia with a surprisingly low fatality rate. 14th April 2020 South Africa had 2272 infections with 27 deaths despite a detailed surveillance system (www.coronavirus.jhu.edu accessed 14th April 2020). It is currently unknown why there has been so far a slower than expected rise in cases and case mortality in low-to-middle income countries. The population demographics and underlying co-morbidities are vastly different in those countries. The mean age of many low-to-middle income countries is more than 2 decades lower than in higher income countries. For example in Uganda the life expectancy at birth for males and females is 60 and 65 years (www.who.org), $48.5 \%$ of the population is in the age range of $0-14$ years old with just $2 \%$ of the population being older than 60 years. This age pyramid influences the current Uganda cardiovascular health challenges which does include hypertension and coronary artery disease, mainly in urban areas, but rheumatic heart disease (RHD) and heart failure due to cardiomyopathies remain enormous challenges. Most of the patients do not have access to balloon valvotomy or surgery [14]. Untreated symptomatic patients with rheumatic heart disease have a mortality rate of $20 \%$ per annum leaving very few patients being able to live beyond their 40 years of age [15]. However, there are other factors which might have an impact. The country-by-country difference in COVID-19 morbidity and mortality could possibly be explained by national policies on Bacillus Calmette Guerin (BCG) vaccination. BCG is a live attenuated strain derived from an isolate of myocobacterium bovis used widely across the world as a vaccine for tuberculosis, with many low-to-middle income countries but also some high-income countries such as Japan having a universal BCG vaccination policy in newborns. BCG vaccinations have been shown to produce non-specific immune effects leading to an improved response against other non-myocardial pathogens. Another possible protective mechanism could be the high number of people living with HIV/AIDS on anti-retroviral therapy. South Africa has a population of 57 million with $>12 \%$ being HIV-infected. SA has the world's largest antiretroviral therapy (ART) program, subsidized by the government and provided free-of-charge. Only time will tell if low-to middle income countries will 'catch up' on the pandemic in 2020 and 2021 or remain relatively spared [16].

The World Heart Federation has published a briefing on prevention: Coronavirus Disease 2019 in low-income countries [17]. This includes six easy rules to reduce the risk of corona virus transmission. From staying at home and avoiding large gathering to a total shut down of a country had so far the biggest impact in a lower number of infections and early case detection.

\section{Hypertension}

\section{The role of the renin-angiotensin-aldosterone system in COVID-19}

The renin-angiotensin-aldosterone system (RAAS) regulates blood pressure and is also involved in cardiovascular endorgan damage like myocardial hypertrophy, interstitial myocardial fibrosis, atherosclerosis and plaque rupture in acute coronary syndromes. Therefore, blockers of the RAAS are recommended for the use in hypertension to prevent cardiovascular events and heart failure [18, 19]. The protease renin cleaves angiotensin to angiotensinogen I (Ang 1-10), which then is processed to angiotensin II (Ang 1-8) by the angiotensin-converting enzyme (ACE) [20]. Angiotensin II stimulates AT1-receptors, which results in adverse cardiovascular effects like vasoconstriction, cell proliferation and hypertrophy [21]. In contrast, the AT2-receptor mediates vasodilation, anti-proliferative actions and apoptosis and has been suggested to be involved in anti-proliferative effects upon binding of angiotensin II [22]. Angiotensin II [1-8] is cleaved by the angiotensin-converting enzyme 2 (ACE2) into angiotensin $(1-7,23)$, which exerts directly a stimulation of the so called "MAS-receptor", mediating vasodilation, anti-proliferative effects and anti-inflammatory responses [24]. It is now well established that the CORONA virus family binds via its spike protein to ACE2 [25, 26] with well characterized binding residues [27]. After proteolytic modification of ACE2 [28] and the coronavirus spike protein $[11,12]$ by a membrane-bound proteinase (ADAM17), the virus is internalized by clathrin-coated pits and, after trypsin cleavage, viral RNA is released into this cellular cytoplasm causing SARS infection [28, 29]. ACE2 is degraded and shedfrom the cell membrane into the circulation after cleavage by ADAM17 [28, 30]. As a result, there is a downregulation of ACE2 by the CORONA virus itself [31]. The role of ACE2 in CORONA virus infection is scrutinized by the fact that several animals cannot be infected by the CORONA virus when there is a knockout of ACE2, which renders them resistant to infection [32]. The role of ACE2 is not specific for the CORONA virus as ACE2 is also used by the respiratory syncytial (RS) virus and some types of influenza viruses [33, 34].

ACE2 can also be regulated in several cardio-pulmonary disease conditions like COPD, pulmonary hypertension, asthma and after viral infections with influenza H1N1, H5N1, H7N9 as well as in sepsis [35]. ACE2, potentially 
by degrading maladaptive angiotensin II and stimulating anti-inflammatory responses through the MAS receptor [24], has been shown to improve lung injury after viral infections of clinical injuries [36]. Furthermore, ARDS is not prominent after RS virus infections, when the ACE2 is knocked out [33]. In addition, recombinant human ACE2 has been tested in a pilot study in human ARDS and has been shown to reduce circulating interleukin- 6 concentrations accompanied by increases of Ang 1-7 and reductions of angiotensin II [37]. Therefore, ACE2 might be crucial for the entry of CORONA viruses into the cells and, hence, infectivity [25-30]; however, it might also mediate beneficial effects on pulmonary complications after infection [36, 37]. The fact that the major risk factor for adverse outcomes in COVID-19 is age, and ACE2 is downregulated in the aging population, argues in favor of its role in poor outcome of that risk group [35]. Furthermore, drugs like chloroquine and indometazine [35] as well as ACE inhibitors and ARBs [38-40] have been shown to upregulate ACE2 in the human heart and in the systemic as well as pulmonary vasculature [40] with association to outcomes in heart failure [41], atrial fibrillation [42] and pulmonary hypertension [43]. These findings highlight the complex interaction of COVID-19 and ACE2 inhibition. We would thus raise the hypothesis that pathophysiological conditions or drugs enhancing ACE2 expression might lead to greater infectivity, but, at the same time potentially reduce mortality due to lung complications (Fig. 3).

\section{Is hypertension a risk factor for COVID-19?}

Arterial hypertension is the most prevalent risk factor in cardiovascular disease, in particular in China [44]. In several early trials of COVID-19 populations, hypertension is the most prevalent cardiovascular risk factor and comorbidity is amounting to approximately $30-40 \%$ in the overall population of diseased individuals in China [7, 45, 46] and Italy [47]. In those patients, who have complications or even died, hypertension is more prevalent as was diabetes, coronary

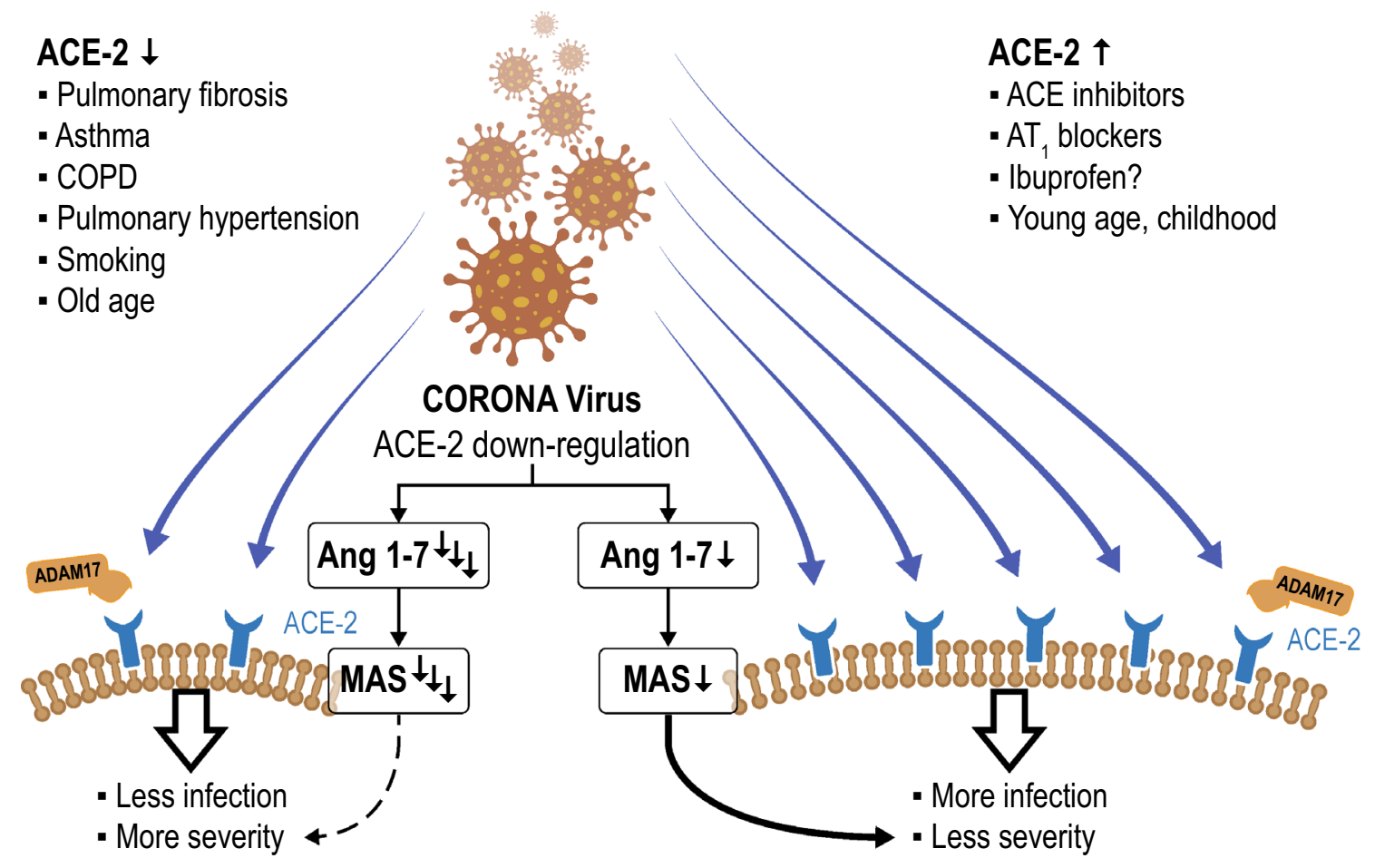

Fig. 3 Hypothetical scheme for the interaction of the CORONA virus and angiotensin converting enzyme-2 (ACE2). The CORONA virus binding with its spike protein to ACE2, which is processed by the proteinase ADAM17 leading to the internalization of the CORONA virus and ACE2 into the cell where the viral genome is released. The internalization as well as the shedding of ACE2 from the cell surface and its release into the circulation reduces membrane-bound ACE2. Furthermore, ACE2 is reduced by pathological conditions like pulmonary fibrosis, asthma, COPD, pulmonary hypertension, smoking and old age [17]. On the contrary, membrane-bound ACE2-concentrations are higher following treatment with ACE-inhibitors, AT1blockers and potentially ibuprofen, and ACE2 is more abundantly expressed in childhood and at young age. As ACE2 forms more Ang 1-7 from angiotension-II to stimulate the MAS-receptor mediating anti-proliferative, anti-inflammatory action, hypothetically enhanced ACE2-expression might cause more infection by acting as a receptor for viral cell entry and protect from pulmonary complications. In conditions where is downregulation of ACE2, less infection might occur, but severity of COVID-19-related ARDS can be more severe. This hypothesis fits with the higher likelihood of pulmonary complications in certain disease conditions and in aging. Notably, these data are derived from experimental and observational data, but not from controlled clinical studies and need to be scrutinized in clinical conditions 
artery disease, chronic obstructive lung disease or malignancies [9]. As hypertension is the comorbidity with the highest prevalence in deceased patients, it has been claimed to be a risk factor for COVID-19. However, this would only be the case, if there is a deviation from the overall prevalence of hypertension in the Chinese population. In China, the prevalence of hypertension is high. By comparing Chinese populations age-matched to those in reports on COVID19 (approximately 55-74 years), it becomes clear that the overall prevalence in hypertension is $44 \%$ with a further increase in populations at higher age [48]. Therefore, the prevalence of the comorbidity hypertension in COVID-19 patients is lower and does not exceed the overall prevalence in the relevant populations in China. Therefore, there is no evidence that hypertension increases the likelihood to suffer from COVID-19. Cardiovascular risk factors and comorbidities are elevated in patients who have fatal outcomes after COVID-19 [9]. Therefore, all cardiovascular comorbidities in concert add to myocardial injury, which has been shown to be closely associated with death as measured from cardiac troponin levels [9].

The next question arises of whether cardiac treatments and treatments with the renin-angiotensin system inhibitors (RASi), in particular ACE-inhibitors (ACE-I) or angiotensin receptor blockers (ARBs) are associated with a differential outcome in COVID-19. The Guidelines for the Management of Hypertension of the European Society of Cardiology [18], but also Chinese guidelines [49] and Guidelines of the American College of Cardiology (ACC) and American Heart Association (AHA) [19] recommend ACE and ARBs for the treatment of hypertension as these drugs have been shown to be effective in secondary prevention, heart failure and protection against adverse renal outcomes. In Germany, as in other countries in Europe, the prescription rate of $\mathrm{ACE}$ and $\mathrm{ARBs}$ are higher than all prescribed daily doses of other anti-hypertensive drugs combined [50]. However, adequate blood pressure control in China in the age group, where COVID-19 is most prevalent, was only $34.9-35.6 \%$ [51] according to the 2010 Chinese guidelines [49] and 15,2-16,0\% according to the 2017 ACC/AHA guidelines [19]. In particular, the frequency of ACE-inhibitor treatment is particularly low in an Asian population (in particular in females), because the ACE-induced coughing is more prevalent than in other populations [51]. Therefore, the low density of treatment with RASi does not argue in favor of a significant role of these drugs in the likelihood of COVID-19. The upregulation of ACE2 by RASi does not allow to argue in favor or against the use of RAS-inhibitors in hypertension as recently expressed in various short communications and letters causing a lot of discussion and media attention [52-58]. Although, a large body of evidence has been generated in cell models, animal models and observational studies, further data are necessary to scrutinize the definite role of ACE2 in infection frequency and causation of pulmonary complications after CORONA infections. At this moment, there is thus no compelling evidentiary background to change RASi therapy for hypertension or other cardiovascular conditions.

\section{COVID-19 and myocardial injury}

The cardiac manifestations of SARS-CoV-2 infection include acute myocardial injury, heart failure, myocarditis, and ventricular tachyarrhythmias [59]. Along with ARDS, acute myocardial injury was identified as an important independent predictor of outcomes, associated with a 3.4-fold higher risk of death [9]. In a cohort of 416 hospitalized patients, the prevalence of cardiac injury-based on the presence of elevated hs-cTnI values above the 99th percentile of a healthy reference population-was $19.7 \%$, and the risk of death increased with the magnitude of myocardial injury, expressed as multiples of the reference value of hs-TnI [9]. Unequivocally, other cohorts investigating the prevalence and prognostic implications of myocardial injury during the COVID-19 outbreak in Wuhan, China, reported very similar rates of acute myocardial injury ranging between $7.2 \%$ [45], $12 \%$ [10], 17\% [7] and 27.8\% [8] at presentation based on elevations of hs-cTn above the ULN. In a report on 138 patients hospitalized with COVID-19 [45], patients who received care in the intensive care unit were more likely to have cardiac injury than non-ICU patients (22.2\% vs $2 \%$ ). 'Consistently, in another study on 41 admitted hospital patients with laboratory-confirmed COVID-19 [10], the proportion of patients requiring care on the intensive care unit (ICU) was significantly higher among patients with evidence of acute myocardial injury ( $31 \%$ vs $4 \%$ ). Several studies demonstrate an association between acute myocardial injury and mortality [7,9]. In a study on 187 patients with COVID-19 that evaluated the role of hs-cTnT relative to the presence of cardiovascular disease [8], mortality rates were highest among patients with elevated hs-cTnT above ULN and history of cardiovascular disease and lowest among those with normal hs-cTn, irrespective the presence or absence of CV disease [8]. In a survey on 416 hospitalized patients in Wuhan [9], only $26.2 \%$ of patients (22 of 82 patients) received an ECG, particularly during periods of elevation of cardiac biomarkers while imaging tests such as echocardiography were not reported. Consistently other reports $[7,60]$ did not report on rates of ECG or other imaging tests, except lung CT, at all. Hence, the limited diagnostic workup and selection bias precludes any speculations on the etiology of hs-cTnI elevation.

Discordant to the recommendations of the 4th version of the universal myocardial infarction (MI) definition (UDMI) [61], the investigators of the Wuhan studies used a different 
definition for acute myocardial injury and did not differentiate acute from chronic myocardial injury by a concentration change ("rise and/or fall") of hs-cTnI. Acute myocardial injury was rather defined as blood levels of high sensitivity troponin $\mathrm{T}$ or I above the 99th percentile upper limit of normal (upper limit of normal (ULN) $>28 \mathrm{ng} / \mathrm{L}$ ), or new abnormalities shown on electrocardiography and echocardiography [10]. The investigators did not report on rates and subtypes of acute myocardial infarction based on criteria of the 4th version of the UDMI [61]. Interestingly, hs-cTn values increased during serial monitoring in patients with a fatal outcome whereas persistently low values were observed among survivors allowing to speculate whether monitoring of hs-cTn might be useful even in the absence of a suspected acute coronary syndrome [7].

Overall, the presence of myocardial injury in ED populations is not uncommon, occurring in as many as $20 \%$ of consecutive patients presenting with chest pain, dyspnea, or less specific symptoms [62]. However, only a fraction of elevations was ultimately attributed to a type 1 or type 2 MI and the majority of cases were unrelated to myocardial ischemia, often multifactorial, or the exact reason remained unsettled [61]. In stable or asymptomatic cardiovascular or ischemic heart disease, cardiac troponin elevation may be explained by the presence of underlying structural heart disease, stable CAD, and chronic kidney disease [63]. Accordingly, in Western countries, the presence of hs-cTn above the 99th percentile ULN has been reported in as many as $20 \%$ of asymptomatic patients with or without cardiovascular disease presenting for routine outpatient visits [63], and across different sub-specialities in patients hospitalized for reasons other than an acute coronary syndrome [64, 65]. Regardless the underlying reason or acuity of clinical presentation, the presence of myocardial injury as indicated by hs-cTn above the 99th percentile is uniformly associated with adverse long-term outcomes and patients with elevated hs-cTn at baseline have a higher risk to die acutely during the precipitating event due to their cardiovascular morbidity [63]. Accordingly, the data from the pandemia in Wuhan, confirm current knowledge but do not provide fundamental new information to our interpretation of troponin elevations.

\section{Acute myocardial injury related to COVID-19}

Based on findings from Corona and Influenza infections in the past, it has been speculated that acute myocardial injury might be triggered or facilitated in COVID-19 infection [59, 66]. A previous study on the incidence of myocardial infarction after the outbreak of Influenza infections in Ontario reported a sixfold higher incidence ratio of AMI within 6 days after a positive Influenza test as compared to a negative test during the same time frame [66]. It was hypothesized that an exaggerated inflammatory response mediated by viral infection with Influenza A or B, respiratory syncytial virus (RSV) or other virus had the potential to trigger acute plaque rupture. In addition, anecdotal evidence from sporadic case reports raised the suspicion of acute myocarditis, although a direct SARS-CoV-2 infiltration of the heart has not been confirmed in the absence of histological confirmation by endocardial biopsy, or by detection of viral genome in myocardial tissue, yet [67]. Previously, a decline in left ventricular ejection fraction (LV-EF) and a highly prevalent reversible, subclinical diastolic left ventricular impairment that was reported in acute SARS-CoV-2 infection and was attributed to the cytokine storm syndrome that is characterized by an uncontrolled and dysfunctional immune response [68]. Finally, cardiotoxic effects of antiviral therapies have been reported [69].

\section{Acute myocardial injury not directly related to COVID-19}

Acute myocardial injury may occur independently from COVID-19 and may manifest as type 1 myocardial infarction (STEMI or NSTEMI), type $2 \mathrm{MI}$ in the absence of plaque rupture or intracoronary thrombus, or as an acute myocardial injury independent of myocardial ischemia (Fig. 4). Cases of acute MI on autopsy during hospitalization for COVID-19 have been reported [7] but a systematic evaluation is lacking. Given the paucity of data on the exact prevalence and reasons for an acute myocardial injury during COVID-19, our interpretation of hs-cTn elevations has to be discussed on knowledge previously derived from other acute critical conditions, foremost severe infections causing sepsis or septic shock [70]. In an investigation on hs-cTnT in setting of severe infection, median concentrations of hs-cTnT were found to increase from $14.4 \mathrm{ng} / \mathrm{L}$ in sepsis to $52.6 \mathrm{ng} / \mathrm{L}$ in severe sepsis and $64.1 \mathrm{ng} / \mathrm{L}$ in septic shock [70]. Likewise, the prevalence of hs-cTnT $>$ ULN increased from 51.6\% in sepsis to $80.4 \% \%$ in septic shock [70]. Very similar to COVID-19, mild elevations of hs-cTnT were associated with a high mortality rate at 30 days [71]. However, the risk associated with myocardial injury at baseline persisted over 5 years after the index event suggesting a major prognostic role of pre-existing structural heart disease on long-term outcomes. Similar to SARS-CoV-2 infection, an impairment of right and left ventricular function on echocardiography was common during other severe infections and there was a clear association between myocardial injury, cardiac overload or hemodynamic stress as indicated by natriuretic peptides and inflammatory response [72]. Significant elevations of hscTn have been demonstrated following rapid atrial pacing, irrespective the presence of inducible myocardial ischemia [73]. In an experimental human model that utilized the trans-cardiac production of lactate for objective evidence of myocardial ischemia, hs-cTnT increased in the absence of 
Fig. 4 Manifestations of myocardial injury and potential pathomechanisms of release of cardiac troponin during COVID-19 infection

\section{Possible causes of myocardial injury and hemodynamic stress}

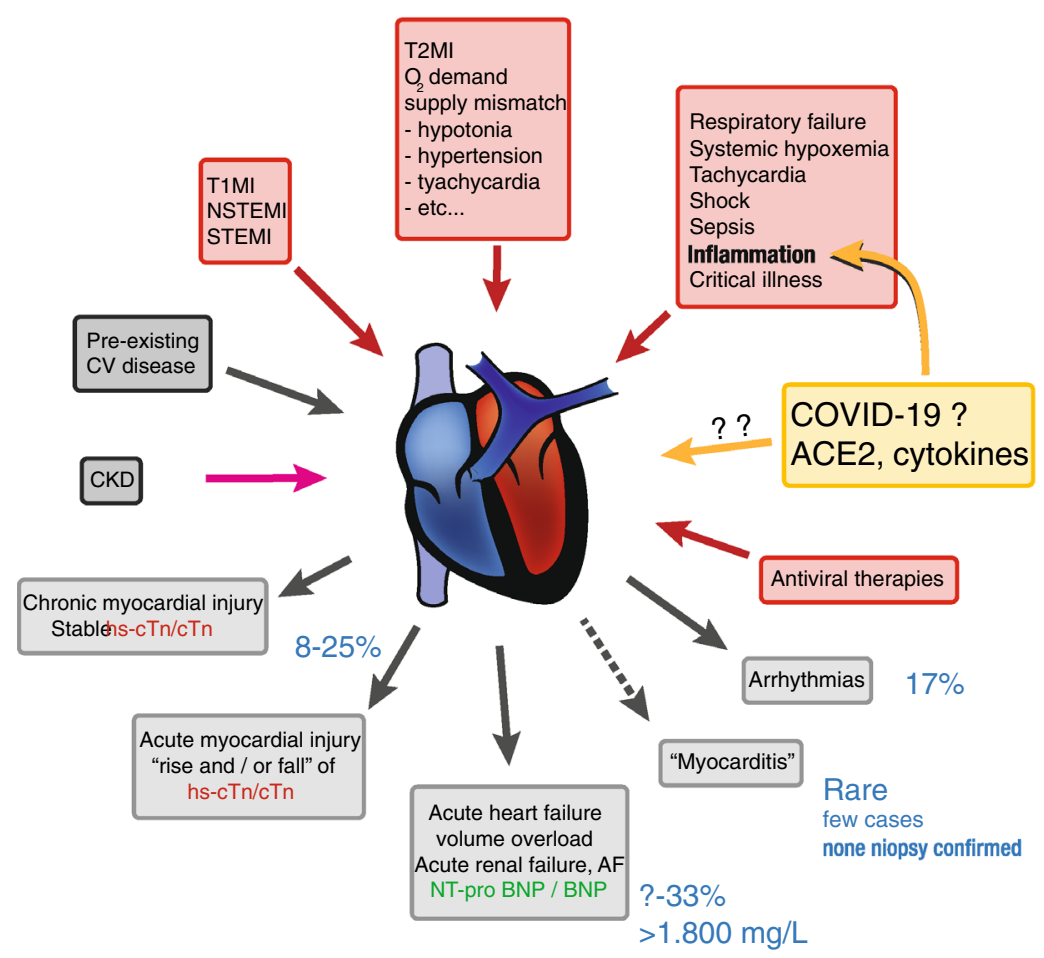

$\mathrm{CAD}$ and lactate suggesting that tachycardia itself is capable to induce an acute myocardial injury. Likewise, administration of catecholamines was found to release hs-cTnT in healthy volunteers [74]. Other mechanisms that have been related to the release of cTn include respiratory failure due to severe hypoxemia, sepsis, acute kidney failure, hypertension or hypotension, bradycardia, fever, anemia and many other causes $[61,63]$.

\section{Practical considerations for patients presenting with suspected or confirmed COVID-19 infection and suspected Type I Myocardial Infarction (T1MI)}

Acute MI with or without COVID-19 represents a lifethreatening condition that requires adjunctive medical therapies such as potent antiplatelet drugs and monitoring to anticipate complications. However, the enhanced infectious potency in humans [75] mandates a fundamental risk assessment to carefully weigh the relative advantages against disadvantages of treating cardiovascular disease while preventing the risk of SARS-CoV-2 transmission.

In patients with suspected ACS without ST-segment elevation, or in the absence of hemodynamic or rhythm instability and when COVID-19 cannot be ruled-out due to suspicious clinical presentation, the personal recommendation of the author is to obtain nasopharyngeal swabs for real-time reverse transcriptase-polymerase chain reaction (RT-PCR) assay and, if available, to perform a CT lung scan while waiting for the PCR result. COVID-19-associated pneumonia provides a typical picture that is characterized by bilateral lung infiltrates, glass ground opacities, consolidation, reticular pattern and the so-called crazy paving pattern [10, 60]. The sensitivity of CT is reported as high as $97-99 \%$ and is superior that of RT-PCR [76]. The CT scan could ideally be performed as a multi-detector CT angiography providing additional information on coronary anatomy and on the presence of pulmonary embolism since elevations of D-Dimer are not uncommon [7, 60] and values exceeding the two-sixfold of the ULN are associated with high mortality [45, 60, 76, 77].

Regarding the measurement of cardiac biomarkers, the American College of Cardiology (ACC) has released statements against the liberal use of troponin in COVID-19 [78]. Given the frequency and non-specific nature of abnormal troponin results among patients with COVID-19, clinicians are advised to measure cardiac troponin only if acute myocardial infarction is suspected on clinical grounds [78]. The European Society of Cardiology (ESC) expands these recommendations by restricting the measurement of cardiac troponin T/I concentrations to patients with suspected Type $1 \mathrm{MI}$, because this infarct type is more likely to benefit from adjunctive antiplatelet therapies and early revascularization therapies (personal communication, paper under revision).

Moreover, in order to reduce the length of stay in an ED, and to dedicate monitoring capacities for other critically diseased patients, accelerated rapid rule-out and/or rule-in of 
MI seem to be particularly helpful [79]. Real world evidence suggests that patient disposition may be completed within 2-3 $\mathrm{h}$ without an increase of adverse outcomes compared to standard protocols [80, 81]. Use of echocardiography or coronary angiography should be restricted to those patients in whom these procedures would be expected to meaningfully affect outcomes [78]. Timing of invasive coronary angiography depends on individual estimation of anticipated risk of death, heart failure or other infarct-related complications. Factors that are supposed to favor an immediate or early coronary angiography under full protection of medical staff include STEMI, high risk non-ST segment elevation MI as suggested by either unstable hemodynamics, dynamic ST segment changes, rhythm instability, or a very high clinical score as recommended in 2015 ESC guidelines [79]. Cardiac troponin values should be interpreted as continuous variables since risk of death and benefits from an early invasive strategy incline with increasing values [82, 83]. It is unclear whether the benefit of revascularization outweighs the potential disadvantages of contamination of medical staff in patients with small-to-intermediate elevations of hs-cTn, or whether a yet unsettled, more refined risk stratification is required to identify those patients who are likely to benefit most [83]. Hence, patients with NSTEMI at lower risk should be managed according to local expertise and capability to deliver echocardiography and invasive procedures effectively to the patient without exposing the medical staff to an increased risk of contamination [84-87].

\section{Heart failure and COVID-19}

\section{Is heart failure a risk factor for COVID-19?}

It has long been known that patients with chronic heart failure (CHF) are at increased risk for adverse consequences of seasonal influenza [88] and other causes of pneumonia [89]. Conversely, infections and in particular pneumonia are frequent triggers of heart failure exacerbations [90]. Of note, influenza vaccination decreases mortality in CHF patients and the beneficial effects of repetitive influenza vaccinations may even exceed those of guideline-directed pharmacotherapy [91]. Severe coronavirus infections such as with SARSCoV-2 have been shown to result in a more severe course of disease in patients with preexisting cardiovascular disease, including heart failure [92]. Thus it is not surprising that COVID-19 is associated with higher morbidity and mortality in patients with cardiovascular comorbidities [7, 93]. Yet, likely due to the lower prevalence of (known) CHF in China, there is still limited specific information on patients with preexisting heart failure. Nevertheless, some early reports [9] indicate that COVID-19 associated myocardial injury (s. below) is more frequent in patients with heart failure and other cardiovascular comorbidities.

\section{Myocardial injury in COVID-19}

Up to $30 \%$ of hospitalized COVID-19 patients $[8,9]$ reveal elevated troponin levels as a marker of myocardial injury. While the precise mechanisms for myocardial necrosis in the context of SARS-CoV-2 is unknown (s. below), troponin elevations are potent predictors of an adverse outcome. Shi et al. [9] reported that increased troponin levels were associated with a higher likelihood for mechanical ventilation, development of ARDS and acute kidney failure. Remarkably, 42 of 82 patients with myocardial injury died (51.2\%), whereas only 15 of 334 troponin negative patients had a lethal outcome. Similarly, Guo et al. [8] showed that an elevated troponin predicted ARDS, ventricular arrhythmias such as VTs VFib and death. Interestingly, a continuous increase in NT-proBNP and troponin T and was observed in those patients that ultimately died, while survivors revealed constant levels. Of note, troponin elevations appear to be more predictive of prognosis than the presence of comorbidities as patients with higher troponin levels but without preexisting cardiovascular or pulmonary disease have a significantly worse prognosis than troponin negative patients with cardiovascular comorbidities (Guo). It seems likely that myocardial injury is not only a marker of an adverse outcome but also a direct cause. This notion is supported by data that show that COVID-19 non-survivors frequently develop heart failure (52\%) and shock (70\%) [7]. Similarly, Ruan et al. [11] reported that in 68 patients who died of COVID-19, myocardial dysfunction was the sole or a contributing factor for death in $40 \%$ of the cases.

\section{Potential mechanisms for myocardial injury in COVID-19}

An obvious reason for an elevated troponin level could be acute coronary syndrome that obviously may also occur in COVID-19 patients, and which is likely to be underdiagnosed due to reluctance for invasive management (s. above). However, the high proportion of typically rather moderately increased high sensitive troponin levels in hospitalized COVID-19 patients renders other explanations more likely, including acute myocarditis due to SARS-CoV-2 or myocardial damage due to proinflammatory cytokines ("cytokine storm"). ACE2 as a potential receptor for Coronavirus infection (s. above) is highly expressed in cardiomyocytes and in vascular pericytes [94]. Thus, it seems plausible that SARSCoV-2 may directly cause viral myocarditis with associated cell death and subsequent myocardial injury as measured by increased troponin levels. Indeed, the first still anecdotal 
autopsy and endomyocardial biopsy reports describe evidence for an acute lymphocytic myocarditis [95, 96]. However, the SARS-CoV-2 genome could not be detected in the myocardium of several of these early cases, indicating that other mechanisms of myocardial injury must be involved, at least in a subset of patients with myocardial injury.

\section{Hyperinflammatory myocardial injury ("cytokine storm")}

Another attractive hypothesis how myocardial injury in the context of COVID-19 may be explained is a hyperinflammatory state where dysregulated cytokines mediate cardiomyocyte stress and ultimately cell death. Such a "cytokine storm" is a well-known [97] while underappreciated syndrome complicating sepsis in up to $4 \%$ of cases [98]. Its clinical characteristics include multiorgan failure associated with persistent fever and lymphopenia as well as high levels of ferritin and several cytokines such as interleukin-6. For example, elevated interleukin-6 (IL-6) levels closely correlate with mortality in sepsis and IL-6 has been shown to directly impair contractile function of cardiomyocytes [99]. Similarly, lymphopenia and excessively elevated ferritin and interleukin-6 levels have been demonstrated in severe cases of COVID-19 which also revealed myocardial injury with increased high sensitive troponin.

\section{Specific treatment of the "cytokine storm" and heart failure in COVID-19?}

Multiple clinical trials are underway which test antiviral agents potentially effective against SARS-CoV-2, such as remdesivir and several antivirals previously shown to be effective eg in HIV infections (reviewed in [100]. As myocardial injury is associated with a dramatically worsened outcome in COVID-19, the question arises whether therapy should also be specifically aimed at the prevention of myocardial damage and/or hyperinflammation. Indeed, the limited experience with inhibition of the cytokine storm by immunosuppression points towards this possibility. For example, interleukin-1 blockade by anakinra has been shown to reduce mortality in sepsis with hyperinflammation [101]. Similarly, tocilizumab, an interleukin-6 receptor blocking antibody, shows early promise in COVID-19: In a non-randomized trial involving 20 patients, CRP levels and oxygen levels were almost normalized within a few days [102]. Other promising targets include JAK inhibitors such as baricitinib [103], immunoglobulins, or fingolimod. Finally, it has even been proposed that angiotensin receptors blockers eg. losartan may not only be not harmful (s. above) in COVID-19, but in fact beneficial as they upregulate ACE2, which could ameriolate tissue damage due to SARS-CoV-2
[104]. Data on removal of cytokines by adsorbent polymer beads ("Cytosorb") are sparse.

\section{Perspectives}

Coronavirus disease 2019 (COVID-19) is a pandemic after an outbreak of pneumonia caused by the novel coronavirus occurred in Wuhan, China. Meanwhile it has spread throughout the world and is associated with mortality rates between 1 to about $5 \%$. Cardiovascular disease is an important risk indicator for adverse outcomes and COVID-19 might affect the cardiovascular system directly. Angiotensin-converting enzyme 2 (ACE2) has been shown to be a coreceptor for viral entry downregulating ACE2 with cardiovascular consequences. Cardiovascular disease with dyspnea as a prime symptom like in heart failure, myocardial ischemia or hypertensive emergency is an important differential diagnosis, should not be ignored in COVID-19 and needs to be recognized as an important indicator of poor outcome. While there is no evidence for changing cardiovascular therapy, a complete cardiovascular workup is necessary in COVID-19 patients and, in particular, in patients with cardio-respiratory symptoms and even in acute respiratory distress syndrome. In turn, cardiopulmonary symptoms should not distract physicians from an unbiased work-up of cardiovascular conditions as these patients could suffer from life-threatening cardiovascular conditions in the absence of COVID-19. Healthcare providers in high, middle and low income countries need to be aware of the importance of cardiovascular disease in patients with SARS and COVID-19 infections by providing optimal cardiovascular care.

\section{References}

1. Cucinotta D, Vanelli M (2020) WHO declares COVID-19 a pandemic. Acta Biomed 91:157-160

2. Spinelli A, Pellino G (2020) COVID-19 pandemic: perspectives on an unfolding crisis. Br J Surg. https://doi.org/10.1002/ bjs. 11627

3. Wu Z, McGoogan JM (2020) Characteristics of and important lessons from the coronavirus disease 2019 (COVID-19) outbreak in China: summary of a report of 72314 cases from the chinese center for disease control and prevention. JAMA. https://doi. org/10.1001/jama.2020.2648

4. Channappanavar R, Perlman S (2017) Pathogenic human coronavirus infections: causes and consequences of cytokine storm and immunopathology. Semin Immunopathol 39:529-539

5. Zeng JH, Liu YX, Yuan J, Wang FX, Wu WB, Li JX, Wang LF, Gao H, Wang Y, Dong CF, Li YJ, Xie XJ, Feng C, Liu L (2020) First case of COVID-19 complicated with fulminant myocarditis: a case report and insights. Infection. https://doi.org/10.1007/ s15010-020-01424-5

6. Kwong JC, Schwartz KL, Campitelli MA, Chung H, Crowcroft NS, Karnauchow T, Katz K, Ko DT, McGeer AJ, McNally D, Richardson DC, Rosella LC, Simor A, Smieja M, Zahariadis G, 
Gubbay JB (2018) Acute myocardial infarction after laboratoryconfirmed influenza infection. N Engl J Med 378:345-353

7. Zhou F, Yu T, Du R, Fan G, Liu Y, Liu Z, Xiang J, Wang Y, Song B, Gu X, Guan L, Wei Y, Li H, Wu X, Xu J, Tu S, Zhang Y, Chen $\mathrm{H}$, Cao B (2020) Clinical course and risk factors for mortality of adult inpatients with COVID-19 in Wuhan, China: a retrospective cohort study. Lancet 395:1054-1062

8. Guo T, Fan Y, Chen M, Wu X, Zhang L, He T, Wang H, Wan J, Wang X, Lu Z (2020) Cardiovascular implications of fatal outcomes of patients with Coronavirus Disease 2019 (COVID-19). JAMA Cardiol. https://doi.org/10.1001/jamacardio.2020.1017

9. Shi S, Qin M, Shen B, Cai Y, Liu T, Yang F, Gong W, Liu X, Liang J, Zhao Q, Huang H, Yang B, Huang C (2020) Association of cardiac injury with mortality in hospitalized patients with COVID-19 in Wuhan, China. JAMA Cardiol. https://doi. org/10.1001/jamacardio.2020.0950

10. Huang C, Wang Y, Li X, Ren L, Zhao J, Hu Y, Zhang L, Fan G, Xu J, Gu X, Cheng Z, Yu T, Xia J, Wei Y, Wu W, Xie X, Yin W, Li H, Liu M, Xiao Y, Gao H, Guo L, Xie J, Wang G, Jiang R, Gao Z, Jin Q, Wang J, Cao B (2020) Clinical features of patients infected with 2019 novel coronavirus in Wuhan. China Lancet 395:497-506

11. Ruan Q, Yang K, Wang W, Jiang L, Song J (2020) Clinical predictors of mortality due to COVID-19 based on an analysis of data of 150 patients from Wuhan, China. Intensive Care Med. https://doi.org/10.1007/s00134-020-05991-x

12. (2020) Lean European Open Survey on SARS-CoV-2 Infected Patients (LEOSS) registry protocols. https://leoss.net/

13. Corrales-Medina VF, Alvarez KN, Weissfeld LA, Angus DC, Chirinos JA, Chang CC, Newman A, Loehr L, Folsom AR, Elkind MS, Lyles MF, Kronmal RA, Yende S (2015) Association between hospitalization for pneumonia and subsequent risk of cardiovascular disease. JAMA 313:264-274

14. Zilla P, Bolman RM, Yacoub MH, Beyersdorf F, Sliwa K, Zühlke L, Higgins RSD, Mayosi B, Carpentier A, Williams D (2018) The Cape Town declaration on access to cardiac surgery in the developing world. J Thorac Cardiovasc Surg 156:2206-2209

15. Lwabi P, Namuyonga J, Lubega S, Oketcho M, Mwambu T, Sebatta E, Okello E, Omagino J, Sliwa K (2019) The Uganda Heart Association. Eur Heart J 40:2396-2397

16. Sliwa K, Ntusi N (2019) Battling cardiovascular diseases in a perfect storm. Circulation 139:1658-1660

17. Thienemann F, Pinto F, Grobbee DE, Boehm M, Bazargani N, Ge J, Sliwa K (2020) World heartfederation briefing on prevention: coronavirus disease 2019 (COVID-19) in low-incomecountries. Glob Heart 15(1):31. https://doi.org/10.5334/gh.778

18. Williams B, Mancia G, Spiering W, Agabiti Rosei E, Azizi M, Burnier M, Clement DL, Coca A, de Simone G, Dominiczak A, Kahan T, Mahfoud F, Redon J, Ruilope L, Zanchetti A, Kerins M, Kjeldsen SE, Kreutz R, Laurent S, Lip GYH, McManus R, Narkiewicz K, Ruschitzka F, Schmieder RE, Shlyakhto E, Tsioufis C, Aboyans V, Desormais I, ESC Scientific Document Group (2018) $2018 \mathrm{ESC} / \mathrm{ESH}$ Guidelines for the management of arterial hypertension. Eur Heart J 39:3021-3104

19. Whelton PK, Carey RM, Aronow WS, Casey DE Jr, Collins KJ, Dennison Himmelfarb C, DePalma SM, Gidding S, Jamerson KA, Jones DW, MacLaughlin EJ, Muntner P, Ovbiagele B, Smith SC Jr, Spencer CC, Stafford RS, Taler SJ, Thomas RJ, Williams KA Sr, Williamson JD, Wright JT Jr (2018) 2017 ACC/AHA/ AAPA/ABC/ACPM/AGS/APhA/ASH/ASPC/NMA/PCNA guideline for the prevention, detection, evaluation, and management of high blood pressure in adults: a report of the American College of Cardiology/American Heart Association task force on clinical practice guidelines. Circulation 138:e426-e483

20. Tipnis SR, Hooper NM, Hyde R, Karran E, Christie G, Turner AJ (2000) A human homolog of angiotensin-converting enzyme. Cloning and functional expression as a captoprilinsensitive carboxypeptidase. J Biol Chem 275:33238-33243

21. Baker KM, Booz GW, Dostal DE (1992) Cardiac actions of angiotensin II: Role of an intracardiac renin-angiotensin system. Annu Rev Physiol 54:227-241

22. Kaschina E, Namsolleck P, Unger T (2017) AT2 receptors in cardiovascular and renal disease. Pharmacol Res 125:39-47

23. Donoghue M, Hsieh F, Baronas E, Godbout K, Gosselin M, Stagliano N, Donovan M, Woolf B, Robison K, Jeyaseelan R, Breitbart RE, Acton S (2000) A novel angiotensin-converting enzyme-related carboxypeptidase (ACE2) converts angiotensin I to angiotensin 1-9. Circ Res 87:E1-9

24. Simões e Silva AC, Silveira KD, Ferreira AJ, Teixeira MM (2013) ACE2, angiotensin-(1-7) and Mas receptor axis in inflammation and fibrosis. Br J Pharmacol 169:477-492

25. Yeager CL, Ashmun RA, Williams RK, Cardellichio CB, Shapiro LH, Look AT, Holmes KV (1992) Human aminopeptidase $\mathrm{N}$ is a receptor for human coronavirus 229E. Nature 357:420-422

26. Turner AJ, Hiscox JA, Hooper NM (2004) ACE2: from vasopeptidase to SARS virus receptor. Trends Pharmacol Sci 25:291-294

27. Chen Y, Guo Y, Pan Y, Zhao Z (2020) Structure analysis of the receptor binding of 2019-nCoV. Biochem Biophys Res Commun. https://doi.org/10.1016/j.bbrc.2020.02.071

28. Lambert DW, Yarski M, Warner FJ, Thornhill P, Parkin ET, Smith AI, Hooper NM, Turner AJ (2005) Tumor necrosis factor-alpha convertase (ADAM17) mediates regulated ectodomain shedding of the severe-acute respiratory syndrome-coronavirus (SARS-CoV) receptor, angiotensin-converting enzyme-2 (ACE2). J Biol Chem 280:30113-30119

29. Walls AC, Park YJ, Tortorici MA, Wall A, McGuire AT, Veesler D (2020) Structure, function, and antigenicity of the SARSCoV-2 spike glycoprotein. Cell. https://doi.org/10.1016/j. cell.2020.02.058

30. Hoffmann M, Kleine-Weber H, Schroeder S, Krüger N, Herrler T, Erichsen S, Schiergens TS, Herrler G, Wu NH, Nitsche A, Müller MA, Drosten C, Pöhlmann S (2020) SARS-CoV-2 cell entry depends on ACE2 and TMPRSS2 and is blocked by a clinically proven protease inhibitor. Cell. https://doi.org/10.1016/j. cell.2020.02.052

31. Dijkman R, Jebbink MF, Deijs M, Milewska A, Pyrc K, Buelow E, van der Bijl A, van der Hoek L (2012) Replication-dependent downregulation of cellular angiotensin-converting enzyme 2 protein expression by human coronavirus NL63. J Gen Virol 93:1924-1929

32. Kuba K, Imai Y, Rao S, Gao H, Guo F, Guan B, Huan Y, Yang P, Zhang Y, Deng W, Bao L, Zhang B, Liu G, Wang Z, Chappell M, Liu Y, Zheng D, Leibbrandt A, Wada T, Slutsky AS, Liu D, Qin C, Jiang C, Penninger JM (2005) A crucial role of angiotensin converting enzyme 2 (ACE2) in SARS coronavirus-induced lung injury. Nat Med 11:875-879

33. Gu H, Xie Z, Li T, Zhang S, Lai C, Zhu P, Wang K, Han L, Duan Y, Zhao Z, Yang X, Xing L, Zhang P, Wang Z, Li R, Yu JJ, Wang $X$, Yang P (2016) Angiotensin-converting enzyme 2 inhibits lung injury induced by respiratory syncytial virus. Sci Rep 6:19840

34. Zou Z, Yan Y, Shu Y, Gao R, Sun Y, Li X, Ju X, Liang Z, Liu Q, Zhao Y, Guo F, Bai T, Han Z, Zhu J, Zhou H, Huang F, Li C, Lu H, Li N, Li D, Jin N, Penninger JM, Jiang C (2014) Angiotensin-converting enzyme 2 protects from lethal avian influenza A H5N1 infections. Nat Commun 5:3594

35. Jia H (2016) Pulmonary angiotensin-converting enzyme 2 (ACE2) and inflammatory lung disease. Shock 46:239-248

36. Imai Y, Kuba K, Rao S, Huan Y, Guo F, Guan B, Yang P, Sarao R, Wada T, Leong-Poi H, Crackower MA, Fukamizu A, Hui CC, Hein L, Uhlig S, Slutsky AS, Jiang C, Penninger JM (2005) 
Angiotensin-converting enzyme 2 protects from severe acute lung failure. Nature 436:112-116

37. Khan A, Benthin C, Zeno B, Albertson TE, Boyd J, Christie JD, Hall R, Poirier G, Ronco JJ, Tidswell M, Hardes K, Powley WM, Wright TJ, Siederer SK, Fairman DA, Lipson DA, Bayliffe AI, Lazaar AL (2017) A pilot clinical trial of recombinant human angiotensin-converting enzyme 2 in acute respiratory distress syndrome. Crit Care 21:234

38. Hamming I, van Goor H, Turner AJ, Rushworth CA, Michaud AA, Corvol P, Navis G (2008) Differential regulation of renal angiotensin-converting enzyme (ACE) and ACE2 during ACE inhibition and dietary sodium restriction in healthy rats. Exp Physiol 93:631-638

39. Ocaranza MP, Godoy I, Jalil JE, Varas M, Collantes P, Pinto M, Roman M, Ramirez C, Copaja M, Diaz-Araya G, Castro P, Lavandero S (2006) Enalapril attenuates downregulation of Angiotensin-converting enzyme 2 in the late phase of ventricular dysfunction in myocardial infarcted rat. Hypertension 48:572-578

40. Ferrario CM, Jessup J, Chappell MC, Averill DB, Brosnihan KB, Tallant EA, Diz DI, Gallagher PE (2005) Effect of angiotensinconverting enzyme inhibition and angiotensin II receptor blockers on cardiac angiotensin-converting enzyme 2. Circulation 111:2605-2610

41. Epelman S, Shrestha K, Troughton RW, Francis GS, Sen S, Klein AL, Tang WH (2009) Soluble angiotensin-converting enzyme 2 in human heart failure: relation with myocardial function and clinical outcomes. J Card Fail 15:565-571

42. Walters TE, Kalman JM, Patel SK, Mearns M, Velkoska E, Burrell LM (2017) Angiotensin converting enzyme 2 activity and human atrial fibrillation: increased plasma angiotensin converting enzyme 2 activity is associated with atrial fibrillation and more advanced left atrial structural remodelling. Europace 19:1280-1287

43. Hemnes AR, Rathinasabapathy A, Austin EA, Brittain EL, Carrier EJ, Chen X, Fessel JP, Fike CD, Fong P, Fortune N, Gerszten RE, Johnson JA, Kaplowitz M, Newman JH, Piana R, Pugh ME, Rice TW, Robbins IM, Wheeler L, Yu C, Loyd JE, West J (2018) A potential therapeutic role for angiotensin-converting enzyme 2 in human pulmonary arterial hypertension. Eur Respir J. https ://doi.org/10.1183/13993003.02638-2017

44. Yang ZJ, Liu J, Ge JP, Chen L, Zhao ZG, Yang WY, China National Diabetes, and Metabolic Disorders Study Group (2012) Prevalence of cardiovascular disease risk factor in the Chinese population: the 2007-2008 China National Diabetes and Metabolic Disorders Study. Eur Heart J 33:213-220

45. Wang D, Hu B, Hu C, Zhu F, Liu X, Zhang J, Wang B, Xiang H, Cheng Z, Xiong Y, Zhao Y, Li Y, Wang X, Peng Z (2020) Clinical characteristics of 138 hospitalized patients with 2019 novel coronavirus-infected pneumonia in Wuhan, China. JAMA. https ://doi.org/10.1001/jama.2020.1585

46. Wu C, Chen X, Cai Y, Xia J, Zhou X, Xu S, Huang H, Zhang L, Zhou X, Du C, Zhang Y, Song J, Wang S, Chao Y, Yang Z, Xu J, Zhou X, Chen D, Xiong W, Xu L, Zhou F, Jiang J, Bai C, Zheng J, Song Y (2020) Risk factors associated with acute respiratory distress syndrome and death in patients with coronavirus disease 2019 pneumonia in Wuhan, China. JAMA Intern Med. https:// doi.org/10.1001/jamainternmed.2020.0994

47. Grasselli G, Zangrillo A, Zanella A, Antonelli M, Cabrini L, Castelli A, Cereda D, Coluccello A, Foti G, Fumagalli R, Iotti G, Latronico N, Lorini L, Merler S, Natalini G, Piatti A, Ranieri MV, Scandroglio AM, Storti E, Cecconi M, Pesenti A, COVID19 Lombardy ICU Network (2020) Baseline characteristics and outcomes of 1591 patients infected with SARS-CoV-2 admitted to ICUs of the Lombardy region, Italy. JAMA. https://doi. org/10.1001/jama.2020.5394
48. Wang Z, Chen Z, Zhang L, Wang X, Hao G, Zhang Z, Shao L, Tian Y, Dong Y, Zheng C, Wang J, Zhu M, Weintraub WS, Gao R, China Hypertension Survey Investigators (2018) Status of hypertension in China: Results from the China hypertension survey, 2012-2015. Circulation 137:2344-2356

49. Liu LS, Writing Group of 2010 Chinese Guidelines for the Management of Hypertension (2011) 2010 Chinese guidelines for the management of hypertension. Zhonghua Xin Xue Guan Bing Za Zhi 39:579-615

50. Schwabe U, Paffrath D, Ludwig WD, Klauber J (2019) Arzneiverordnungs-Report 2019.https://doi.org/10.1007/978-3662-59046-1

51. Lu J, Lu Y, Wang X, Li X, Linderman GC, Wu C, Cheng X, Mu L, Zhang H, Liu J, Su M, Zhao H, Spatz ES, Spertus JA, Masoudi FA, Krumholz HM, Jiang L (2017) Prevalence, awareness, treatment, and control of hypertension in China: data from 1.7 million adults in a population-based screening study (China PEACE Million Persons Project). Lancet 390:2549-2558

52. Kuster GM, Pfister O, Burkard T, Zhou Q, Twerenbold R, Haaf P, Widmer AF, Osswald S (2020) SARS-CoV2: should inhibitors of the renin-angiotensin system be withdrawn in patients with COVID-19? Eur Heart J. https://doi.org/10.1093/eurheartj/ehaa2 35

53. Bavishi C, Maddox TM, Messerli FH (2020) Coronavirus Disease 2019 (COVID-19) infection and renin angiotensin system blockers. JAMA Cardiol. https://doi.org/10.1001/jamacardio .2020 .1282

54. Patel AB, Verma A (2020) COVID-19 and angiotensin-converting enzyme inhibitors and angiotensin receptor blockers: what is the evidence? JAMA. https://doi.org/10.1001/jama.2020.4812

55. Fang L, Karakiulakis G, Roth M (2020) Are patients with hypertension and diabetes mellitus at increased risk for COVID-19 infection? Lancet Respir Med 8:e21. https://doi.org/10.1016/ S2213-2600(20)30116-8

56. Sommerstein R, Gräni C (2020) Preventing a COVID-19 pandemic: ACE inhibitors as a potential risk factor for fatal COVID19. BMJ 368:m810

57. Diaz JH (2020) Hypothesis: angiotensin-converting enzyme inhibitors and angiotensin receptor blockers may increase the risk of severe COVID-19. Travel Med. https://doi.org/10.1093/ jtm/taaa041

58. Esler M, Esler D (2020) Can angiotensin receptor-blocking drugs perhaps be harmful in the COVID-19 pandemic? J Hypertens 38:781-782

59. Xiong TY, Redwood S, Prendergast B, Chen M (2020) Coronaviruses and the cardiovascular system: acute and long-term implications. Eur Heart J. https://doi.org/10.1093/eurheartj/ehaa2 31

60. Chen N, Zhou M, Dong X et al (2020) Epidemiological and clinical characteristics of 99 cases of 2019 novel coronavirus pneumonia in Wuhan, China: a descriptive study. Lancet 395(10223):507-513. https://doi.org/10.1016/S0140 $-6736(20) 30211-7$

61. Thygesen K, Alpert JS, Jaffe AS et al (2019) Fourth universal definition of myocardial infarction (2018). Eur Heart J 40:237269. https://doi.org/10.1093/eurheartj/ehy462

62. Mueller M, Biener M, Vafaie M et al (2012) Absolute and relative kinetic changes of high-sensitivity cardiac troponin $\mathrm{T}$ in acute coronary syndrome and in patients with increased troponin in the absence of acute coronary syndrome. Clin Chem 58(1):209-218

63. Giannitsis E, Katus HA (2013) Cardiac troponin level elevations not related to acute coronary syndromes. Nat Rev Cardiol 10(11):623-634. https://doi.org/10.1038/nrcardio.2013.129

64. McFalls EO, Larsen G, Johnson GR et al (2011) Outcomes of hospitalized patients with non-acute coronary syndrome and 
elevated cardiac troponin level. Am J Med 124(7):630-635. https://doi.org/10.1016/j.amjmed.2011.02.024

65. Iversen K, Køber L, Gøtze JP et al (2013) Troponin T is a strong marker of mortality in hospitalized patients. Int J Cardiol 168(2):818-824

66. Kwong JC, Schwartz KL, Campitelli MA et al (2018) Acute myocardial infarction after laboratory-confirmed influenza infection. N Engl J Med 378(4):345-353. https://doi. org/10.1056/NEJMoa1702090

67. Inciardi RM, Lupi L, Zaccone G, Italia L, Raffo M, Tomasoni D, Cani DS, Cerini M, Farina D, Gavazzi E, Maroldi R, Adamo M, Ammirati E, Sinagra G, Lombardi CM, Metra M (2020) Cardiac involvement in a patient with Coronavirus Disease 2019 (COVID-19). JAMA Cardiol. https://doi.org/10.1001/ jamacardio.2020.1096

68. Li SS, Cheng CW, Fu CL et al (2003) Left ventricular performance in patients with severe acute respiratory syndrome: a 30-day echocardiographic follow-up study. Circulation 108(15):1798-1803. https://doi.org/10.1161/01.CIR.00000 94737.21775 .32

69. Varga ZV, Ferdinandy P, Liaudet L, Pacher P (2015) Druginduced mitochondrial dysfunction and cardiotoxicity. Am J Physiol Heart Circ Physiol 309(9):H1453-H1467. https://doi. org/10.1152/ajpheart.00554.2015(Epub 2015 Sep 18)

70. Wilhelm J, Hettwer S, Schuermann M et al (2014) Elevated troponin in septic patients in the emergency department: frequency, causes, and prognostic implications. Clin Res Cardiol 103(7):561-567. https://doi.org/10.1007/s00392-014-0684-4

71. Vasile VC, Chai HS, Abdeldayem D, Afessa B, Jaffe AS (2013) Elevated cardiac troponin T levels in critically ill patients with sepsis. Am J Med 126(12):1114-1121. https:// doi.org/10.1016/j.amjmed.2013.06.029

72. Landesberg G, Jaffe AS, Gilon D et al (2014) Troponin elevation in severe sepsis and septic shock: the role of left ventricular diastolic dysfunction and right ventricular dilatation*. Crit Care Med 42(4):790-800. https://doi.org/10.1097/CCM.00000 00000000107

73. Turer AT, Addo TA, Martin JL et al (2011) Myocardial ischemia induced by rapid atrial pacing causes troponin $\mathrm{T}$ release detectable by a highly sensitive assay: insights from a coronary sinus sampling study. J Am Coll Cardiol 57(24):2398-2405. https://doi.org/10.1016/j.jacc.2010.11.066

74. Siriwardena M, Campbell V, Richards AM, Pemberton CJ (2012) Cardiac biomarker responses to dobutamine stress echocardiography in healthy volunteers and patients with coronary artery disease. Clin Chem 58(10):1492-1494

75. Lai A, Bergna A, Acciarri C, Galli M, Zehender G (2020) Early phylogenetic estimate of the effective reproduction number of SARS-CoV-2. J Med Virol. https://doi.org/10.1002/jmv.25723 (Epub ahead of print)

76. Ai T, Yang Z, Hou H et al (2020) Correlation of chest CT and RT-PCR testing in Coronavirus Disease 2019 (COVID19) in China: a report of 1014 cases. Radiology. https://doi. org/10.1148/radiol.2020200642(published online ahead of print, 2020 Feb 26)

77. Tang N, Li D, Wang X, Sun Z (2020) Abnormal coagulation parameters are associated with poor prognosis in patients with novel coronavirus pneumonia. J Thromb Haemost 18(4):844847. https://doi.org/10.1111/jth.14768

78. https://www.acc.org/lates t-incardiology/articles/2020/03/18/15/25/troponin-and-bnp-use-in-covid19

79. Roffi M, Patrono C, Collet JP et al (2016) 2015 ESC Guidelines for the management of acute coronary syndromes in patients presenting without persistent ST-segment elevation: Task Force for the Management of Acute Coronary Syndromes in Patients Presenting without Persistent ST-Segment Elevation of the European Society of Cardiology (ESC). Eur Heart J 37(3):267-315

80. Stoyanov KM, Hund H, Biener M et al (2020) RAPID-CPU: a prospective study on implementation of the ESC 0/1-hour algorithm and safety of discharge after rule-out of myocardial infarction. Eur Heart J Acute Cardiovasc Care 9(1):39-51

81. Twerenbold R, Costabel JP, Nestelberger T et al (2019) Outcome of applying the ESC 0/1-hour algorithm in patients with suspected myocardial infarction. J Am Coll Cardiol 74(4):483-494. https://doi.org/10.1016/j.jacc.2019.05.046

82. Lindahl B, Venge P, James S (2010) The new high-sensitivity cardiac troponin $\mathrm{T}$ assay improves risk assessment in acute coronary syndromes. Am Heart J 160(2):224-229. https://doi. org/10.1016/j.ahj.2010.05.023(published correction appears in Am Heart J. 2011 Feb;161(2):425)

83. Jobs A, Mehta SR, Montalescot G et al (2017) Optimal timing of an invasive strategy in patients with non-ST-elevation acute coronary syndrome: a meta-analysis of randomised trials. Lancet 390(10096):737-746. https://doi.org/10.1016/S0140 $-6736(17) 31490-3$

84. (2020) ACC Clinical Bulletin: COVID 19 Clinical Guidance For the CV Care Team. https://www.acc.org/ /media/Non-Clinical/ Files-PDFs-Excel-MS-Word-etc/2020/02/S20028-ACC-ClinicalBulletin-Coronavirus.pdf. Accessed 13 April 2020

85. Driggin E, Madhavan MV, Bikdeli B, Chuich T, Laracy J, BondiZoccai G, Brown TS, Nigoghossian C, Zidar DA, Haythe J, Brodie D, Beckman JA, Kirtane AJ, Stone GW, Krumholz HM, Parikh SA (2020) Cardiovascular Considerations for Patients, Health Care Workers, and Health Systems During the Coronavirus Disease 2019 (COVID-19) Pandemic. J Am Coll Cardiol. https://doi.org/10.1016/j.jacc.2020.03.031

86. https://dgk.org/daten/echo-anleitung-in-zeiten-von-covid-19_ final-1.pdf

87. American College of Cardiology (2020) COVID-19 Clinical Guidance For the Cardiovascular Care Team. https://www. acc.org/ /media/Non-Clinical/Files-PDFs-Excel-MS-Wordetc/2020/02/S20028-ACC-Clinical-Bulletin-Coronavirus.pdf. Accessed 15 May 2020

88. Alon D, Stein GY, Korenfeld R, Fuchs S (2013) Predictors and outcomes of infection-related hospital admissions of heart failure patients. PLoS ONE 8:e72476. https://doi.org/10.1371/journ al.pone. 0072476

89. Sandoval C, Walter SD, Krueger P, Smieja M, Smith A, Yusuf S, Loeb MB (2007) Risk of hospitalization during influenza season among a cohort of patients with congestive heart failure. Epidemiol Infect 135:574-582. https://doi.org/10.1017/S095026880 $600714 \mathrm{X}$

90. Kytömaa S, Hegde S, Claggett B, Udell JA, Rosamond W, Temte J, Nichol K, Wright JD, Solomon SD, Vardeny O (2019) Association of influenza-like illness activity with hospitalizations for heart failure: the atherosclerosis risk in communities study. JAMA Cardiol 4(4):363-369. https://doi.org/10.1001/jamacardio .2019 .0549

91. Modin D, Jorgensen ME, Gislason G, Jensen JS, Kober L, Claggett B, Hegde SM, Solomon SD, Torp-Pedersen C, BieringSørensen T (2019) Influenza vaccine in heart failure: cumulative number of vaccinations, frequency, timing, and survival: a Danish Nationwide Cohort Study. Circulation 139:575-589. https ://doi.org/10.1161/CIRCULATIONAHA.118.036788

92. Chan JW, Ng CK, Chan YH, Mok TY, Lee S, Chu SY, Law WL, Lee MP, Li PC (2003) Short term outcome and risk factors for adverse clinical outcomes in adults with severe acute respiratory syndrome (SARS). Thorax 58(8):686-689

93. Li B, Yang J, Zhao F, Zhi L, Wang X, Liu L, Bi Z, Zhao Y (2020) Prevalence and impact of cardiovascular metabolic diseases on COVID-19 in China. Clin Res Cardiol 109:531-538 
94. Chen L, Hao G (2020) The role of angiotensin-converting enzyme 2 in coronaviruses/influenza viruses and cardiovascular disease. Cardiovasc Res. https://doi.org/10.1093/cvr/cvaa093

95. Sala S, Peretto G, Gramegna M, Palmisano A, Villatore A, Vignale D, De Cobelli F, Tresoldi M, Cappelletti AM, Basso C, Godino C, Esposito A (2020) Acute myocarditis presenting as a reverse Tako-Tsubo syndrome in a patient with SARS-CoV-2 respiratory infection. Eur Heart J. https://doi.org/10.1093/eurhe artj/ehaa286

96. Yao XH, Li TY, He ZC et al (2020) A pathological report of three covid-19 cases by minimally invasive autopsies. Zhonghua Bing Li Xue Za Zhi 49:E009

97. Karakike E, Giamarellos-Bourboulis EJ (2019) Macrophage activation-like syndrome: a distinct entity leading to early death in sepsis. Front Immunol 31(10):55. https://doi.org/10.3389/fimmu .2019 .00055

98. Mehta P, McAuley DF, Brown M, Sanchez E, Tattersall RS, Manson JJ, HLH Across Speciality Collaboration, UK (2020) COVID-19: consider cytokine storm syndromes and immunosuppression. Lancet 395(10229):1033-1034. https://doi. org/10.1016/S0140-6736(20)30628-0

99. Pathan N, Hemingway CA, Alizadeh AA, Stephens AC, Boldrick JC, Oragui EE, McCabe C, Welch SB, Whitney A, O'Gara
P, Nadel S, Relman DA, Harding SE, Levin M (2004) Role of interleukin 6 in myocardial dysfunction of meningococcal septic shock. Lancet 363(9404):203-209

100. Madjid M, Safavi-Naeini P, Solomon SD, Vardeny O (2020) Potential effects of coronaviruses on the cardiovascular system: a review. JAMA Cardiol. https://doi.org/10.1001/jamacardio .2020 .1286

101. Shakoory B, Carcillo JA, Chatham WW, Amdur RL, Zhao H, Dinarello CA, Cron RQ, Opal SM (2016) Interleukin-1 receptor blockade is associated with reduced mortality in sepsis patients with features of macrophage activation syndrome: reanalysis of a prior phase III trial. Crit Care Med 44(2):275-281. https://doi. org/10.1097/CCM.0000000000001402

102. Xu X, Han M, Li T, Sun W, Wang D, Fu B, Zhou Y, Zheng X, Yang Y, Li X, Zhang X, Pan A, Wei H. Effective treatment of severe COVID-19 patients with tocilizumab. PNAS. https://doi. org/10.1073/pnas.2005615117

103. Favalli EG, Biggioggero M, Maioli G, Caporali R (2020) Baricitinib for COVID-19: a suitable treatment? Lancet Infect Dis. https://doi.org/10.1016/S1473-3099(20)30262-0

104. (2020) Losartan for patients with COVID-19 requiring hospitalization. ClinicalTrials.gov Identifier: NCT04312009. 